\title{
Tumor-targeted IL-12 combined with tumor resection yields a survival-favorable immune profile
}

Qingnan Zhao ${ }^{1 \dagger}$, Jiemiao Hu ${ }^{1 \dagger}$, Abhisek Mitra², Jeffry Cutrera ${ }^{3}$, Wendong Zhang ${ }^{1}$, Zhongting Zhang ${ }^{1}$, Jun Yan ${ }^{1}$, Xueqing Xia ${ }^{1}$, Kris Michael Mahadeo ${ }^{4}$, John Andrew Livingston ${ }^{5}$, Richard Gorlick ${ }^{1}$ and Shulin Li ${ }^{1,6^{*}}$ (D)

\begin{abstract}
Background: Although accumulated evidence provides a strong scientific premise for using immune profiles to predict survival in patients with cancer, a universal immune profile across tumor types is still lacking, and how to achieve a survival-associated immune profile remains to be evaluated.
\end{abstract}

Methods: We analyzed datasets from The Cancer Genome Atlas to identify an immune profile associated with prolonged overall survival in multiple tumor types and tested the efficacy of tumor cell-surface vimentin-targeted interleukin 12 (tIIL-12) in inducing that immune profile and prolonging survival in both mouse and patient-derived xenograft tumor models.

Results: We identified an immune profile (IFNY ${ }^{\text {Hi }} \mathrm{CD} 8^{\mathrm{Hi}} \mathrm{FOXP} 3^{\mathrm{LOw}} \mathrm{CD} 33^{\text {Low }}$ ) associated with prolonged overall survival across several human tumor types. ttIL-12 in combination with surgical resection of the primary tumor transformed tumors to this immune profile. Intriguingly, this immune profile transformation led to inhibition of metastasis and to prolonged survival in both mouse and patient-derived xenograft malignant models. Wild-type IL-12 combined with surgery was significantly less effective. In the IL-12-sensitive C3H mouse strain, in fact, wild-type IL-12 and surgery resulted in shorter overall survival than in mice treated with control pDNA; this surprising result is believed to be attributable to IL-12 toxicity, which was absent in the mice treated with ttIL-12. The ttIL-12-induced immune profile associated with longer overall survival was also associated with a greater accumulation of $\mathrm{CD} 8^{+} \mathrm{T}$ cells and reduced infiltration of regulatory $T$ cells, myeloid-derived suppressor cells, and tumor-associated macrophages. The underlying mechanism for this transformation by ttIL-12 treatment was induction of expression of CXCL9 and reduction of expression of CXCL2 and CCL22 in tumors.

Conclusions: $\mathrm{ttlL}-12$ when combined with surgery led to conversion to the IFNY ${ }^{\mathrm{Hi}} \mathrm{CD} 8^{\mathrm{Hi}} \mathrm{FOXP} 3^{\mathrm{Low}} \mathrm{CD} 33^{\mathrm{LOw}}$ immune profile, eliminated relapse and metastasis, and prolonged overall survival.

Keywords: Tumor-targeted IL-12, Surgical resection, Immune profile, Overall survival

\section{Introduction}

Communication between tumor cells and the associated immune system is pivotal for tumor metastasis, relapse, and progression. Since Rudolf Virchow first proposed the link between tumorigenesis and chronic inflammation,

\footnotetext{
* Correspondence: Sli4@mdanderson.org

${ }^{\dagger}$ Qingnan Zhao and Jiemiao Hu contributed equally to this work.

'Department of Pediatrics-Research, The University of Texas MD Anderson Cancer Center, Houston, TX 77030, USA

${ }^{6}$ Department of Pediatrics-Research, The University of Texas MD Anderson Cancer Center, 1515 Holcombe Boulevard, Unit 853, Houston, TX 77054, USA Full list of author information is available at the end of the article
}

myriad studies have contributed to the characterization of immune cell-associated tumor progression and treatment resistance [1-3]. Some of these studies have shown that a favorable immune environment may boost a tumor's response to treatment [4], including chemotherapy [5], immunotherapy [6,7], and irradiation [8]. These observations reinforce the need to better understand the prognostic impact of immune cells on the tumor and its microenvironment and on clinical outcome.

The primary immune cells in tumors are tumorinfiltrating lymphocytes, myeloid cells, and macrophages,

(c) The Author(s). 2019 Open Access This article is distributed under the terms of the Creative Commons Attribution 4.0 International License (http://creativecommons.org/licenses/by/4.0/), which permits unrestricted use, distribution, and reproduction in any medium, provided you give appropriate credit to the original author(s) and the source, provide a link to the Creative Commons license, and indicate if changes were made. The Creative Commons Public Domain Dedication waiver (http://creativecommons.org/publicdomain/zero/1.0/) applies to the data made available in this article, unless otherwise stated. 
which consist of both immunostimulatory populations and immunosuppressive populations. Accumulating evidence shows that immunostimulatory populations, such as $\mathrm{CD}^{+} \mathrm{T}$ cells, natural killer (NK) cells, type 1 helper $\mathrm{T}$ cells, and M1 macrophages, efficiently boost antitumor immune responses [9]. Immunosuppressive populations, including myeloid-derived suppressor cells (MDSCs), regulatory $\mathrm{T}$ cells (Tregs), and tumor-associated macrophages, are mobilized during tumorigenesis and relapse. After infiltrating into developing tumors, MDSCs promote tumor vascularization and disrupt immunosurveillance, including M1 macrophage polarization, antigen presentation [10], T cell activation [11], and NK cell cytotoxicity [12]. Similar to MDSCs, Tregs suppress tumor-associated antigen presentation and disrupt cytotoxic $\mathrm{T}$ cell function [13]. Tregs regulate the expansion and activation of $\mathrm{T}$ and $B$ cells and have a pivotal role in maintaining the homeostasis of innate cytotoxic lymphocytes [14]. In various reports, a high frequency of $\mathrm{CD}^{+}$tumor-infiltrating lymphocytes [15] or a low frequency of MDSCs [16] or $\mathrm{FOXP3}^{+}$Tregs [17] in tumors was associated with longer survival in the targeted tumor types. However, the optimal immune profile for effectively predicting patient survival across tumor types and the approaches to achieving such an optimal immune profile are largely unknown.

Interleukin 12 (IL-12), which bridges adaptive and innate immune responses, is accepted as a central antitumor immunotherapeutic agent. Although systemic delivery of IL-12 (e.g., IL-12-secreting T cells) has substantial anticancer efficacy, it causes significant toxic effects in humans [18]. To ameliorate this toxicity, we developed an IL-12 that targets cell-surface vimentin (CSV), a protein found on the surfaces of tumor cells across tumor types, especially metastatic tumors [19, 20]. Administration of tumor CSV-targeted IL-12 (ttIL12), a fusion gene that encodes IL-12 and a comprehensive CSV-targeting carcinoma homing peptide, increased tumor accumulation of IL-12 in vivo [19], and ttIL-12 therapy via intramuscular electroporation promoted the inhibition of tumor growth with less liver toxicity than wild-type IL-12 (wtIL-12) therapy [19]. While ttIL-12 may modify dendritic cells in tumors [19], its overall impact on the tumor immune profile has not been investigated.

Our purpose in this study was to identify an immune profile that is consistently associated with longer survival across different cancers and to investigate a therapeutic intervention that can transform a short overall survival (OS) immune profile into the long OS immune profile. By analyzing The Cancer Genome Atlas (TCGA) data across different human tumors for markers of immunostimulatory interferongamma (IFNy)-positive $\mathrm{CD}^{+}$cytotoxic $\mathrm{T}$ cells and immunosuppressive Tregs and MDSCs, we found that the immune profile IFN $\gamma^{\mathrm{Hi}} \mathrm{CD} 8 \mathrm{a}^{\mathrm{Hi}} \mathrm{FOXP} 3{ }^{\mathrm{Low}} \mathrm{CD} 33^{\mathrm{Low}}$ predicted excellent patient outcome across different tumor types. Notably, ttIL-12 converted immune profiles associated with shorter survival to the immune profile associated with longer survival in two independent mouse tumor models (one mesenchymal tumor and one epithelial tumor) and one patientderived xenograft (PDX) model (osteosarcoma). Mechanistic studies found that ttIL-12 treatment increased the expression of T cell-recruiting chemokine CXCL9 and IFNY and reduced the expression of MDSC- and Treg-recruiting CXC-chemokine ligand 2 (CXCL2) and CC-chemokine ligand 22 (CCL22) in tumors. Overexpression of CXCL2 or CCL22, or depletion of CD8a, impaired ttIL-12's efficacy in suppressing tumor growth and metastasis, which validated the novel mechanism of ttIL-12 in converting a short OS immune profile to a long OS immune profile.

\section{Materials and methods TCGA data mining}

Gene expression and survival data were obtained from the TCGA portal (http://www.cbioportal.org/public-por$\mathrm{tal} /$ ). Copy numbers of the CD8a, IFN $\gamma, \mathrm{CD} 33$, and FOXP3 genes and survival data were obtained for eight cancer types: breast adenocarcinoma, sarcoma, lung adenocarcinoma, liver cancer, head and neck squamous cell carcinoma, colon carcinoma, ovarian carcinoma, and melanoma.

\section{Plasmid DNA preparation}

All gene constructs were generated as previously described [19]. The wild-type IL-12 plasmid DNA (pDNA), CCL22 DNA (pCCL22), and CXCL2 DNA (pCXCL2) were obtained from Genscript (New Jersey, USA), and the ttIL-12 pDNA was described previously [19]. The control pDNA (Ctrl) was wtIL-12 with the IL-12 gene deleted.

\section{Cell lines}

The $4 \mathrm{~T} 1$ murine breast cancer cell line and LM8 murine osteosarcoma cell line were obtained from ATCC (Manassas, VA). Both cell lines were maintained in Dulbecco modified Eagle medium containing 10\% fetal bovine serum (Life Technologies, Carlsbad, CA) at $37^{\circ} \mathrm{C}$ and in an atmosphere containing $5 \% \mathrm{CO}_{2}$.

\section{Animals and tumor models}

$\mathrm{BALB} / \mathrm{c}$ and $\mathrm{C} 3 \mathrm{H}$ female mice were obtained from The Jackson Laboratory (Bar Harbor, ME), and CB17SC scid $^{-/}$female mice were purchased from Taconic Farms (Germantown, NY). All were 6 to 8 weeks old upon initiation of the experiments. Detailed information can be found in the supplementary material.

In brief, orthotopic $4 \mathrm{~T} 1$ and LM8 tumors were initiated by inoculating $1 \times 10^{5}$ cells in the third mammary fat pads of the $\mathrm{BALB} / \mathrm{c}$ mice and in the right tibia of 
$\mathrm{C} 3 \mathrm{H}$ mice, respectively. The first pDNA treatments $(10 \mu \mathrm{g}$; wtIL-12, ttIL-12, or Ctrl) via intramuscular electroporation were performed as described previously [19]; a second identical treatment was administered 10 days later. For metastatic tumor analysis, 4 T1-bearing mice and LM8-bearing mice were euthanized 20 days or 5 days after primary tumor removal, respectively, and lungs, livers, and bones were collected to analyze metastatic status. India ink inflation was performed to determine the level of lung metastasis, and white metastatic nodules were counted using a dissecting microscope.

To overexpress CCL22 and CXCL2 in vivo, $10 \mu \mathrm{g}$ pCCL22 or pCXCL2 was administered via intramuscular electroporation into $4 \mathrm{~T} 1$ - and LM8-bearing mice 3 days prior to ttIL-12 treatment as described above. Seven days after the second treatment, orthotopic $4 \mathrm{~T} 1$ and LM8 tumors were collected for later analysis.

For the PDX model, patient-derived OS60-SJ osteosarcoma tumor cells (generously provided by Dr. Richard Gorlick, the Pediatric Preclinical Testing Consortium, The University of Texas MD Anderson Cancer Center) were implanted subcutaneously into $\mathrm{CB17SC} \mathrm{scid}^{-/-}$female mice. When tumors reached $300 \mathrm{~mm}^{3}$ in size, the mice were treated with Ctrl, human wtIL-12, or human ttIL-12 pDNA as already described once per week for 4 weeks. To make these CB17SC scid $^{-/-}$mice immunocompetent, they were injected with $2 \times 10^{7}$ human peripheral blood mononuclear cells (PBMCs) intravenously every 2 weeks along with pDNA treatment.

\section{Immunohistology staining}

Formalin-fixed, paraffin-embedded lung and liver tissue sections were stained with hematoxylin and eosin (H\&E; Sigma Chemical, St Louis, MO). Frozen tumor sections were fixed with cold acetone, acetone plus chloroform (1:1), and acetone. Tissue sections were blocked with blocking buffer (5\% normal horse serum and 1\% normal goat serum in phosphate-buffered saline solution) and incubated with rat anti-mouse $\mathrm{CD} 8 \alpha$ antibody (clone YTS105.18; AbD Serotec, Raleigh, NC). For FOXP3 staining, sections were blocked with blocking buffer containing $0.1 \%$ Triton X-100 for $40 \mathrm{~min}$ and incubated with rat anti-FOXP3 antibody (\#12653; Cell Signaling Technology, Danvers, MA) overnight at $4{ }^{\circ} \mathrm{C}$. The next day, tissue sections were blocked and incubated with goat anti-rat horseradish peroxidase secondary antibody (Life Technologies) for $1 \mathrm{~h}$ at room temperature, which was followed by DAB staining for $5 \sim 10 \mathrm{~min}$ at room temperature. Nuclei were then counterstained with hematoxylin (Sigma Chemical), and tumor sections were mounted with ClearMount Mounting Solution (Life Technologies). Slides were visualized under a Nikon eclipse Ti fluorescence microscope (Nikon Instruments, Melville, NY).

\section{Immune cell depletion in vivo}

During the mouse model experiment just described, an antibody depleting $\mathrm{CD}^{+} \mathrm{T}$ cells $(250 \mu \mathrm{g}$ per mouse; clone 2.43) was administered intraperitoneally to mice twice a week for 3 weeks starting on day 3 after tumor cell inoculation.

\section{Flow cytometry}

Portions of primary tumor and metastatic tissues were digested with collagenase IV/DNase $(0.2 \mathrm{mg} / \mathrm{mL}$ and $10 \mu \mathrm{g} / \mathrm{mL}$ ) at $37^{\circ} \mathrm{C}$ for $30 \mathrm{~min}$. Cells were put through $40-\mu \mathrm{m}$ filters to obtain single-cell suspensions and stained as previously described [21]. Cell surfaces were stained with anti-mouse CD4, anti-mouse CD206, antimouse CD11b, anti-mouse F4/80, anti-mouse Gr1.1, anti-mouse $\mathrm{CD} 3$, anti-mouse CD45, anti-mouse CD8a, anti-mouse CD28, anti-mouse NKG2D, anti-human CD45, anti-human CD8, anti-human CD33, and antihuman HLA-DR antibodies (BioLegend, San Diego, CA) labeled with fluorescein isothiocyanate, PerCP/Cy5.5, phycoerythrin, or Brilliant Violet 421. Flow cytometry was performed using an Attune flow cytometer (Life Technologies), and the data were analyzed with FlowJo software.

\section{RNA isolation and quantitative real-time PCR}

Total RNA was isolated from tumor tissues using TRIzol reagent (Thermo Fisher Scientific, Waltham, MA) according to the manufacturer's instructions. Equal amounts of RNA were reverse-transcribed into cDNA by using iScript ${ }^{\mathrm{max}}$ gDNA Clear cDNA Synthesis Kit (BioRad, Berkeley, CA). qRT-PCR was performed using the Power SYBR Green Master kit (Thermo Fisher Scientific, Waltham, MA), with a StepOnePlus ${ }^{\mathrm{Tm}}$ Real-Time PCR System (Thermo Fisher Scientific, Waltham, MA), as previously described [22]. The level of mRNA expression was normalized to that of the housekeeping gene GAPDH. The primer sequences of all mouse genes can be found in supplementary materials.

\section{Enzyme-linked immunosorbent assay}

The IL-12 and IFNY proteins in mouse tumors were measured in triplicate by commercially available kits (R\&D Systems, Minneapolis, MN) by following the manufacturer's instructions. Mouse CCL22, CXCL9, CXCL10, CCL5, and CXCL2 proteins were assayed by using commercial kits from Biolegend (mouse proinflammatory chemokine mix and match subpanel).

\section{Statistical analysis}

For each reported result, data were pooled from at least two independent experiments. The Student $t$-test was used to compare results between two treatment groups; one-way ANOVA was used to compare results from 
more than two treatment groups. The statistical significance of differences in survival curves was determined by log-rank survival analysis. All quantified data are presented as mean \pm standard deviation (SD) or as indicated. The Prism software (GraphPad Software, Inc., La Jolla, CA) was used to determine the $P$ values, and $P$ values $<0.05$ were considered statistically significant.

\section{Results}

An immune profile associated with longer overall survival Mutation-induced oncogene activation and tumor suppressor gene inactivation have been widely investigated as markers to predict survival duration for patients with cancer. However, no one mutation is known to universally predict OS duration across different tumor types. This is not surprising, because different tumors may utilize different pathways or oncogenes to drive tumor progression and metastasis. However, immune profile infiltration is a common factor across all tumor types. Indeed, some studies have found that a certain type of immune profile was associated with long-term OS [23, 24]. T cell infiltration and frequency of FOXP3 ${ }^{+}$Tregs, MDSCs, and tumor-associated macrophages all have been discussed in the literature as predictors of OS in specific tumor types $[25,26]$, but none were analyzed across multiple types of tumors. Our first goal for this study was to identify a single immune profile that can universally predict long-term OS across different tumor types. Our second goal was to develop a simple immune therapy that converts tumors from an immune profile associated with short OS to the immune profile associated with longer OS.

To identify an immune profile associated with prolonged survival, we focused on $\mathrm{T}$ cell activation markers and immunosuppressive cell markers in an analysis of TCGA data. Our rationale was that functional $\mathrm{T}$ cells in tumors are effective in eliminating tumor cells and enhancing responses to chemotherapy, radiation, or other treatments. Although CD69, CD29, and CD25 are T cell activation markers, these markers are found in many other cells [27-29]. IFN $\gamma$ is also not $\mathrm{T}$ cell specific, but its expression in $\mathrm{T}$ cells and other immune cells is a fairly good indicator of survival. In fact, IFN $\gamma^{\mathrm{Hi}}$ alone is reasonably accurate in predicting OS rate (Fig. 1a,c), but the predicted OS rates are not very high in some types of tumors (Additional file 1: Table S1). For example, the OS rates of patients with IFN $\gamma^{\mathrm{Hi}}$ lung cancer or melanoma were 23.6 .4 and $39.7 \%$, respectively (Additional file 1: Table S1). To refine the profile toward longer OS, we added the CD8 gene; the combination of IFN $\gamma^{\mathrm{Hi}}$ and $\mathrm{CD} 8^{\mathrm{Hi}}$ improved accuracy of identification of patients with longer OS, but further inclusion of parameters indicating low expression levels of immunosuppressive cell markers, such as FOXP3 and CD33, even more greatly improved the accuracy of the combination's prediction of longer OS. For example, including these two immunosuppressive markers in the profile increased the predicted OS rate from 54.1 to $68 \%$ in patients with sarcoma (Fig. 1b,d). This observation makes sense because CD33 is a key marker for MDSCs and FOXP3 is a key indicator for Tregs, and both Tregs and MDSCs can shut down $\mathrm{T}$ cell activity by secreting unfavorable molecules such as IL-10, transforming growth factor beta (TGF- $\beta$ ), IL-35, and arginase 1 (Arg1) [30, 31]. Of course, inclusion of additional genes may further improve the accuracy of prediction of OS rate, but further expansion of the combination of biomarkers would have hampered utility for OS analysis across tumor types in the TCGA database, because some datasets lack data on RNAs or genes of interest. Expanding the biomarker panel may also limit its clinical application. However, these four genes, at the indicated expression levels, together predict long-term OS in multiple types of tumors (Additional file 1: Table S1). Our results strongly indicate that the $\mathrm{CD} 8 \mathrm{a}^{\mathrm{Hi}} \mathrm{IFN} \gamma{ }^{\mathrm{Hi}} \mathrm{CD} 33^{\mathrm{Low}} \mathrm{FOXP} 3^{\mathrm{Low}}$ immune profile is associated with long-term OS across multiple tumor types.

ttIL-12 treatment converts primary tumors to the immune profile associated with long-term OS

The consistent association of the $\mathrm{CD} 8 \mathrm{a}^{\mathrm{Hi}} \mathrm{IFN} \gamma{ }^{\mathrm{Hi}} \mathrm{C}$ D33 ${ }^{\text {Low }}{ }^{\text {FOXP }} 3^{\text {Low }}$ immune profile with long-term OS suggests that any treatment that can convert tumors to this immune profile may prolong OS. In our attempts to identify such a treatment, we have investigated several reagents, but all failed. This study describes our investigation of the impact of ttIL-12 on the immune profiles of two different common tumors. ttIL-12 (US patent 9, 657,077 B2) was selected because this product targets a universal tumor-specific protein, CSV, and promotes accumulation of IL-12 in tumors [19].

We first assayed the effect of ttIL-12 on tumor progression using two aggressive orthotopic mouse tumor models: an epithelial tumor (4 T1, breast carcinoma) and a mesenchymal tumor (LM8, sarcoma). BALB/c mice bearing a $4 \mathrm{~T} 1$ tumor and $\mathrm{C} 3 \mathrm{H}$ mice bearing an LM8 tumor were treated with empty (Ctrl), wtIL-12, or ttIL12 pDNA. As expected, ttIL-12 treatment showed higher potency in suppressing tumor growth than wtIL-12 treatment in both $4 \mathrm{~T} 1$ and LM8 models (Additional file 1: Figure S1).

We then evaluated the effect of ttIL-12 on immune profile in tumors. $\mathrm{CD}^{+} \mathrm{T}$ cells, Tregs, and MDSCs were assayed using antibodies against CD8a, FOXP3, and CD11b/Gr1, respectively. To our surprise, ttIL-12 treatment not only increased numbers of $\mathrm{CD}^{+} \mathrm{T}$ cells but also decreased numbers of $\mathrm{FOXP}^{+}$Tregs and MDSCs in $4 \mathrm{~T} 1$ tumors compared with both Ctrl treatment and 


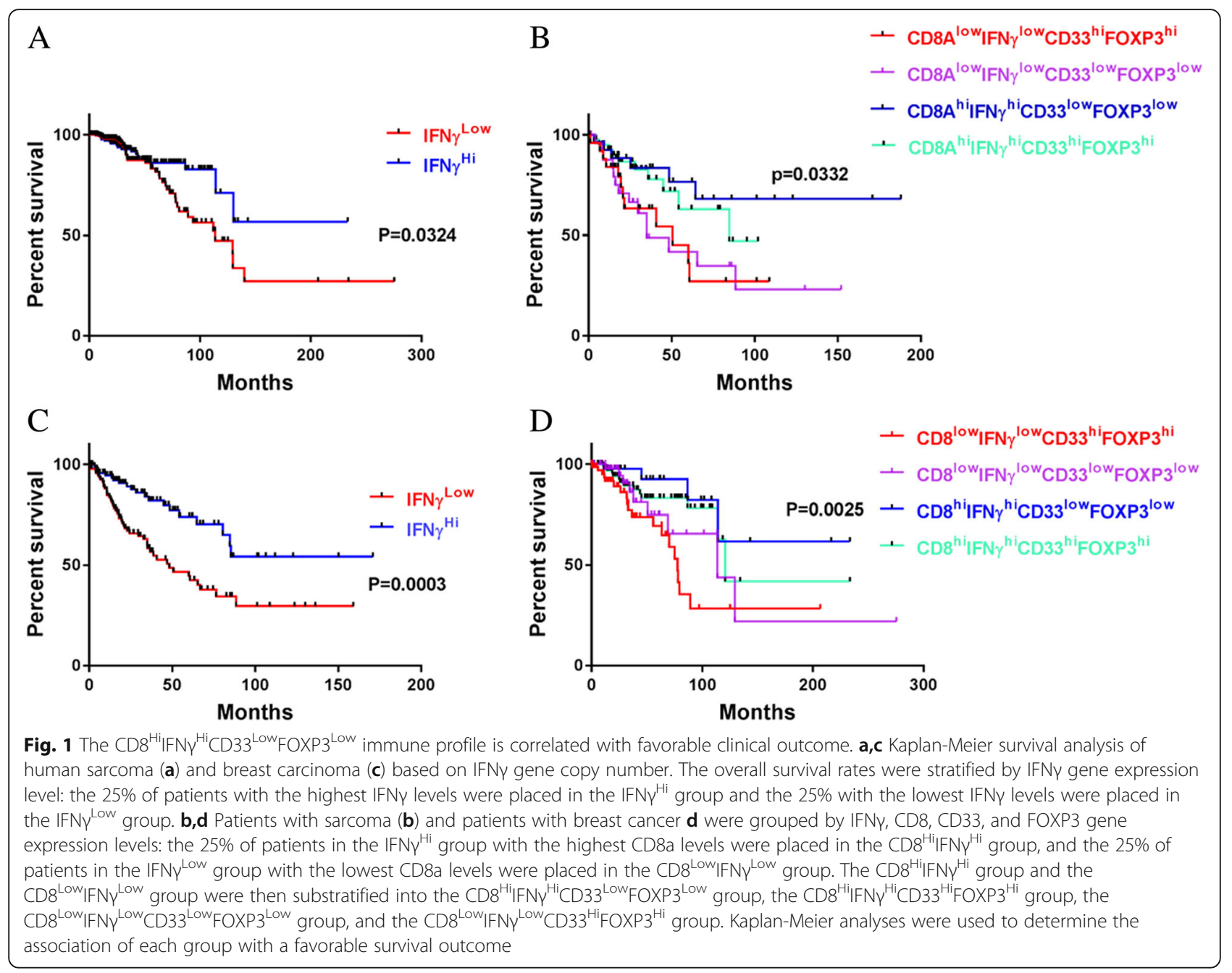

wtIL-12 treatment (Fig. 2). ttIL-12 treatment also decreased M2 macrophages in tumors, as determined by using antibodies against F4/80/CD11b/CD206 (Additional file 1: Figure S2). Similar results were obtained in the LM8 model (Additional file 1: Figure S3). These results suggest that ttIL-12 has extra independent biological function on top of the known IL-12 function, which is to block immune suppression. We also measured the tumor levels of IL-12 and IFN $\gamma$ proteins, which can overcome the suppressive tumor microenvironment and shift the balance to favor $\mathrm{CD}^{+} \mathrm{T}$ cell antitumor immunity. Our data show that tumors treated with ttIL-12 accumulated more IL-12 and expressed higher levels of IFN $\gamma$ than those treated with wtIL-12 (Fig. 2e; $P=0.0024$ ). Notably, the ratio of $\mathrm{CD}^{+} \mathrm{T}$ cells to Tregs in ttIL-12-treated tumors was significantly higher than in wtIL-12-treated tumors (Fig. 2c; $P=0.0092$ ), which shows that ttIL- 12 has higher potency than wtIL-12 therapy in inducing the immune profile associated with longer OS.

To expand our evaluation of ttIL-12 treatment, the antitumor effect of wtIL-12 and ttIL-12 on human tumor progression was measured in an osteosarcoma PDX model. According to our data, the antitumor effect of ttIL-12 is dependent on the immune system. Therefore, human PBMCs were injected in combination with the pDNA into CB17SC $\mathrm{scid}^{-/-}$mice bearing an OS60-SJ osteosarcoma tumor. The tumors treated with ttIL-12 showed dramatically higher levels of IFNY than those treated with $\mathrm{Ctrl}(P<0.05)$, higher frequency of $\mathrm{CD} 8^{+} \mathrm{T}$ cells $(P=0.0358)$, and lower frequencies of MDSCs $(P=$ $0.0458)$ and Tregs $(P=0.0059)$ (Additional file 1: Figure S8), suggesting that ttIL-12 treatment converted the immune profile in these osteosarcoma PDX tumors to the IFN $\gamma^{\mathrm{Hi}} \mathrm{CD} 8{ }^{\mathrm{Hi}} \mathrm{FOXP} 3{ }^{\mathrm{Low}} \mathrm{CD} 33^{\mathrm{Low}}$ immune profile associated with longer OS.

\section{ttIL-12 treatment followed by surgery suppresses metastasis in two independent tumor models}

To investigate the potential impact of the combination of ttIL-12 treatment and surgery on metastasis, $4 \mathrm{~T} 1$ or LM8 tumor-bearing mice treated with ttIL-12, wtIL-12, or Ctrl underwent surgical removal of the primary 


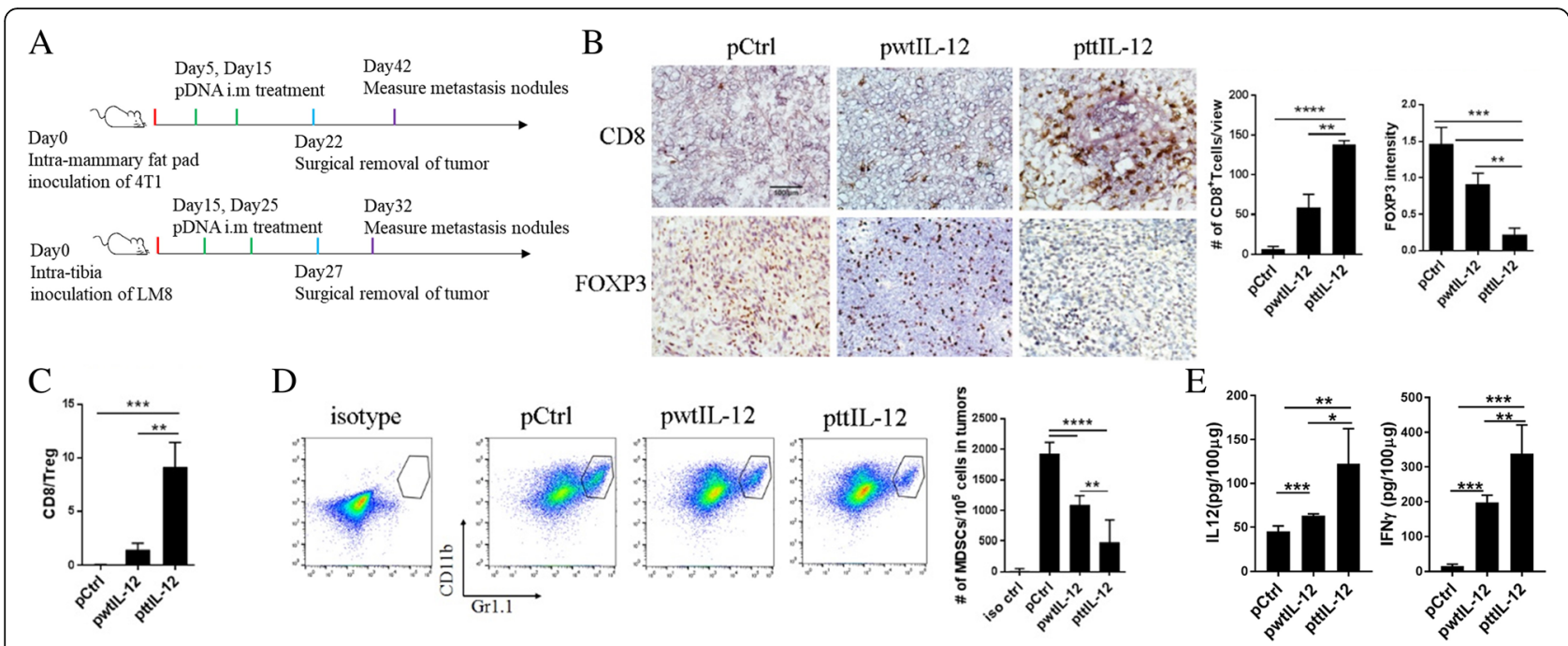

Fig. 2 ttIL-12 enhanced infiltration of CD8 ${ }^{+} T$ cells into tumors, decreased infiltration of Tregs and MDSCs, and increased tumor levels of IFNy. (a) Treatment scheme. BALB/c mice were inoculated with $4 \mathrm{~T} 1$ breast cancer cells by intra-mammary fat pad injection. $\mathrm{CH} 3$ mice were inoculated with LM8 sarcoma cells by intratibial injection. Mice from both groups were treated with empty control plasmid DNA (pDNA; pCtrl), wild-type IL12 pDNA (pwtlL-12), or tumor-targeted IL-12 pDNA (pttIL-12; $n=5 \sim 8$ mice per treatment group). Primary tumors were removed surgically as indicated. b Frozen sections from 4T1 primary tumors were stained with CD8 antibody (upper panels) or FOXP3 antibody (lower panels). FOXP3 is a marker of T regulatory cells (Tregs). Representative sections are shown. Scale bars, $100 \mu \mathrm{m}$. Absolute numbers of CD8 ${ }^{+}$cells and FOXP3 ${ }^{+}$cells were determined by microscopy. c Calculated $\mathrm{CD} 8^{+} /$Treg ratios. $\mathbf{d}$ Representative flow cytometry plots of percentages of $\mathrm{CD} 11 \mathrm{~b}^{+} \mathrm{Gr} 1^{+}$cells (myeloid-derived suppressor cells [MDSCs]); absolute numbers of MDSCs per $10^{5}$ total tumor cells were calculated from the flow cytometry data. e Levels of the IL-12 and IFNY proteins in primary 4T1 tumors were measured by ELISA. ${ }^{*} P<0.05,{ }^{* *} P<0.01,{ }^{* * *} P<0.001,{ }^{* * * *} P<0.0001$

orthotopic tumor after the pDNA treatment, and the metastatic tumor nodules in their lungs and livers were counted 20 days (4 T1) or 5 days (LM8) later. Numbers of metastatic nodules in the lungs were lower in the 4 T1 mice treated with ttIL-12 plus surgery $(\mathrm{ttIL}-12+\mathrm{S})$ than in those treated with wtIL-12 plus surgery (wtIL$12+S$ ), as validated via $H \& E$ staining in lungs and livers. Numbers of lung metastatic nodules were dramatically lower in 4 T1-bearing mice treated with ttIL-12+ S than in those treated with control plasmid plus surgery $(\mathrm{Ctrl}+\mathrm{S})$, while wtIL-12+S slightly decreased lung metastatic nodules in both $4 \mathrm{~T} 1$ and LM8 tumor-bearing mice (Fig. 3a, c). Moreover, ttIL-12+S decreased liver metastatic nodules in the LM8 model compared with wtIL-12 + S (Fig. 3b; $P=0.0044$ ). Together, these data show that ttIL-12+S had greater anti-metastatic effect than wtIL-12 $+\mathrm{S}$ in both sarcoma and breast carcinoma models.

ttIL-12 treatment converts metastatic tumors from shortto long-term OS immune profile

To identify the mechanism that may account for the enhanced anti-metastatic effect of ttIL-12 $+\mathrm{S}$, we analyzed the metastatic nodules in lungs and livers of LM8 tumor-bearing mice for infiltrated $\mathrm{CD}^{+} \mathrm{T}$ cells, MDSCs, and Tregs using flow cytometry and immunohistochemical staining. Mice treated with ttIL-12+S showed higher frequencies of $\mathrm{CD}^{+} \mathrm{T}$ cells $(P<0.0001)$ and lower frequencies of MDSCs $(P<0.0001)$ and Tregs $(P<0.001)$ in lung metastatic nodules than mice treated with wtIL-12+S (Fig. 4, Additional file 1: Figure S4), which was consistent with ttIL-12's role in inducing the $\mathrm{CD} 8 \mathrm{a}^{\mathrm{Hi}} \mathrm{IFN} \gamma{ }^{\mathrm{Hi}} \mathrm{CD} 33^{\mathrm{Low}} \mathrm{FOXP} 3{ }^{\mathrm{Low}}$ immune profile in primary orthotopic tumors. Similar results were found in the liver metastatic nodules of LM8 tumor-bearing mice (Additional file 1: Figure S5).

Previous reports showed that infiltrated NKG2D ${ }^{+} \mathrm{CD} 8^{+}$ $\mathrm{T}$ cells in tumors exert effector functions in the tumor microenvironment, attack tumor cells, induce tumor cell death, and significantly halt tumor progression [22]. To understand whether these infiltrated $\mathrm{CD}^{+} \mathrm{T}$ cells in metastatic nodules were tumor-responsive or exhausted, we analyzed the metastatic nodules for CD28 and NKG2D, co-stimulatory receptors that serve as nonexhaustion markers. 4 T1 tumor-bearing mice treated with ttIL-12+S showed higher proportions of both $\mathrm{CD} 28^{+} \mathrm{CD}^{+} \mathrm{T}$ cells and NKG2D ${ }^{+} \mathrm{CD} 8^{+} \mathrm{T}$ cells in lung metastatic nodules than mice treated with wtIL-12+S or $\mathrm{Ctrl}+\mathrm{S}$ (Additional file 1: Figure S4). Similarly, ttIL-

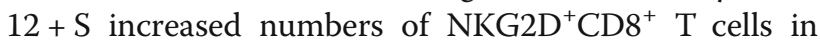
livers of LM8 tumor-bearing mice (Additional file 1: Figure S5A), showing that ttIL-12 $+\mathrm{S}$ induced its greater anti-metastatic effect, compared with wtIL-12+S, through activating non-exhausting $\mathrm{CD} 8^{+} \mathrm{T}$ cells.

To further validate the significance of $\mathrm{CD}^{+} \mathrm{T}$ cells in the anti-metastatic effect of ttIL-12, both $4 \mathrm{~T} 1$ and LM8 


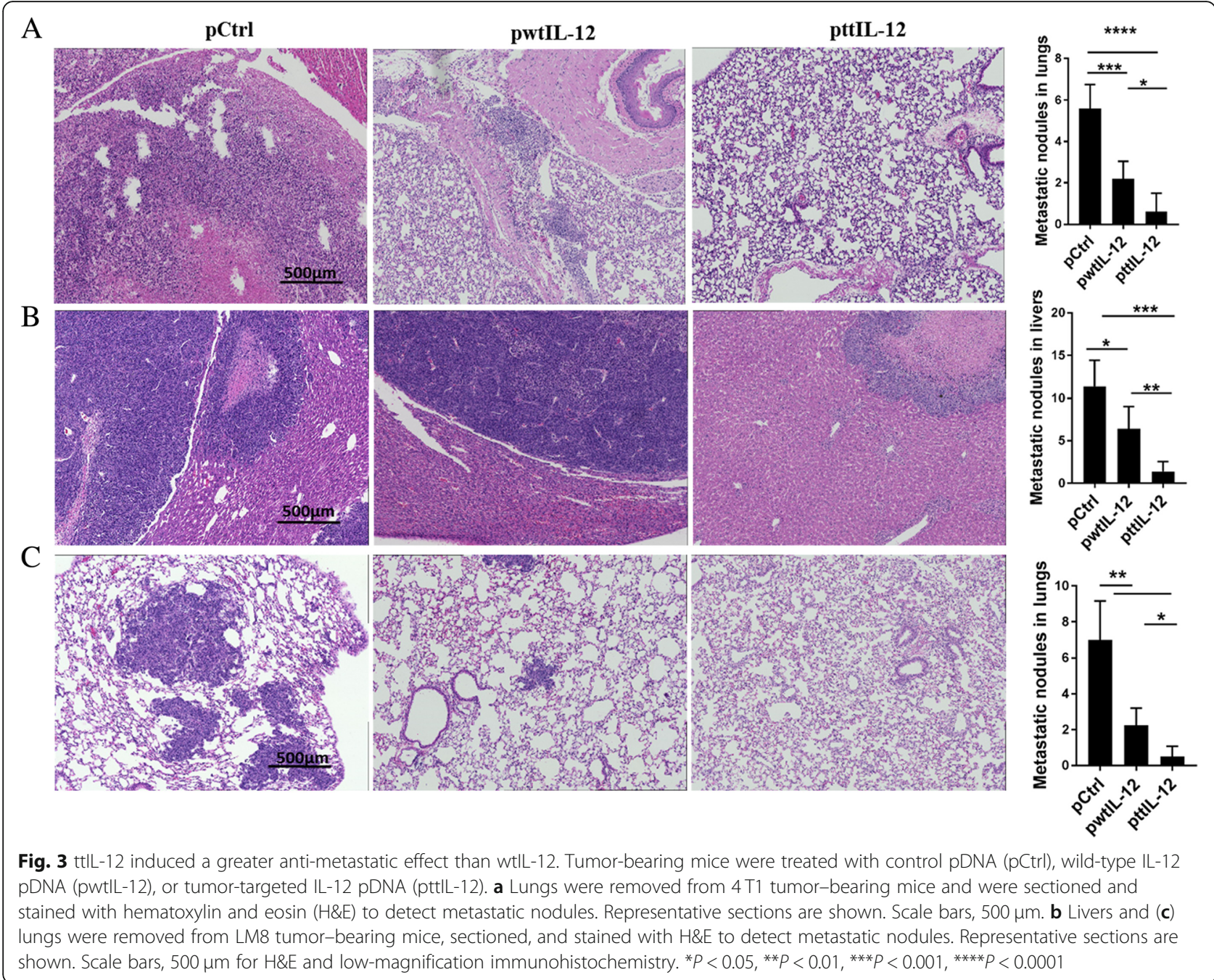

tumor-bearing mice were treated with CD8-depleting antibody along with ttIL-12. As expected, blocking CD8 significantly dampened the survival-favorable effect of ttIL-12 treatment in both models (Fig. 6a, b; $P<0.0001$ and $P=0.0105$, respectively), suggesting that $\mathrm{CD}^{+} \mathrm{T}$ cells are pivotal in the suppression of tumor progression by ttIL-12+S.

\section{ttIL-12 treatment increases chemokines that recruit $\mathrm{CD}^{+}$ $T$ cells but reduces chemokines that recruit MDSCs and Tregs}

To understand the mechanism underlying the impact of ttIL-12 treatment on immune profile change in tumors, we used RT-PCR to analyze the tumors for several chemokines and cytokines known to participate in the migration and recruitment of $\mathrm{CD}^{+} \mathrm{T}$ cells, Tregs, and MDSCs. Although both ttIL-12 and wtIL-12 significantly increased levels of CCL5, which recruits $\mathrm{CD}^{+} \mathrm{T}$ cells into tumors, ttIL-12 treatment was more effective than wtIL-12 treatment in increasing tumor levels of IFN $\gamma$ and decreasing tumor levels of CCL22 and CXCL2 (Additional file 1: Figure S6B), chemokines that recruit Tregs and MDSCs, respectively. To validate these mRNA-based gene expression results, an ELISA assay was performed. This assay confirmed that ttIL-12 treatment significantly increased the quantities of IFN $\gamma$ protein (Fig. 2e) and reduced the quantities of CCL22 and CXCL2 proteins in tumors, compared with wtIL-12 treatment (Fig. 5a, Additional file 1: Figure S6C). Moreover, measurement of levels of CXCL9 and CXCL10 proteins, which are $\mathrm{CD}^{+} \mathrm{T}$ cell attractants, showed that ttIL-12 increased CXCL9 levels in both primary tumor and lung metastatic nodules in the $4 \mathrm{~T} 1$ and LM8 models, while ttIL-12 increased CXCL10 levels only in lung metastatic tumors in the $4 \mathrm{~T} 1$ model and liver metastatic tumors in the LM8 model (Fig. 5a, Additional file 1: Figure $\mathrm{S} 6 \mathrm{C}$ ). Together, these findings indicate that ttIL-12 increases $\mathrm{CD} 8^{+} \mathrm{T}$ cell frequency in tumors and is associated with increases in expression of IFNY and CXCL9 and that ttIL-12 decreases frequencies of Tregs 


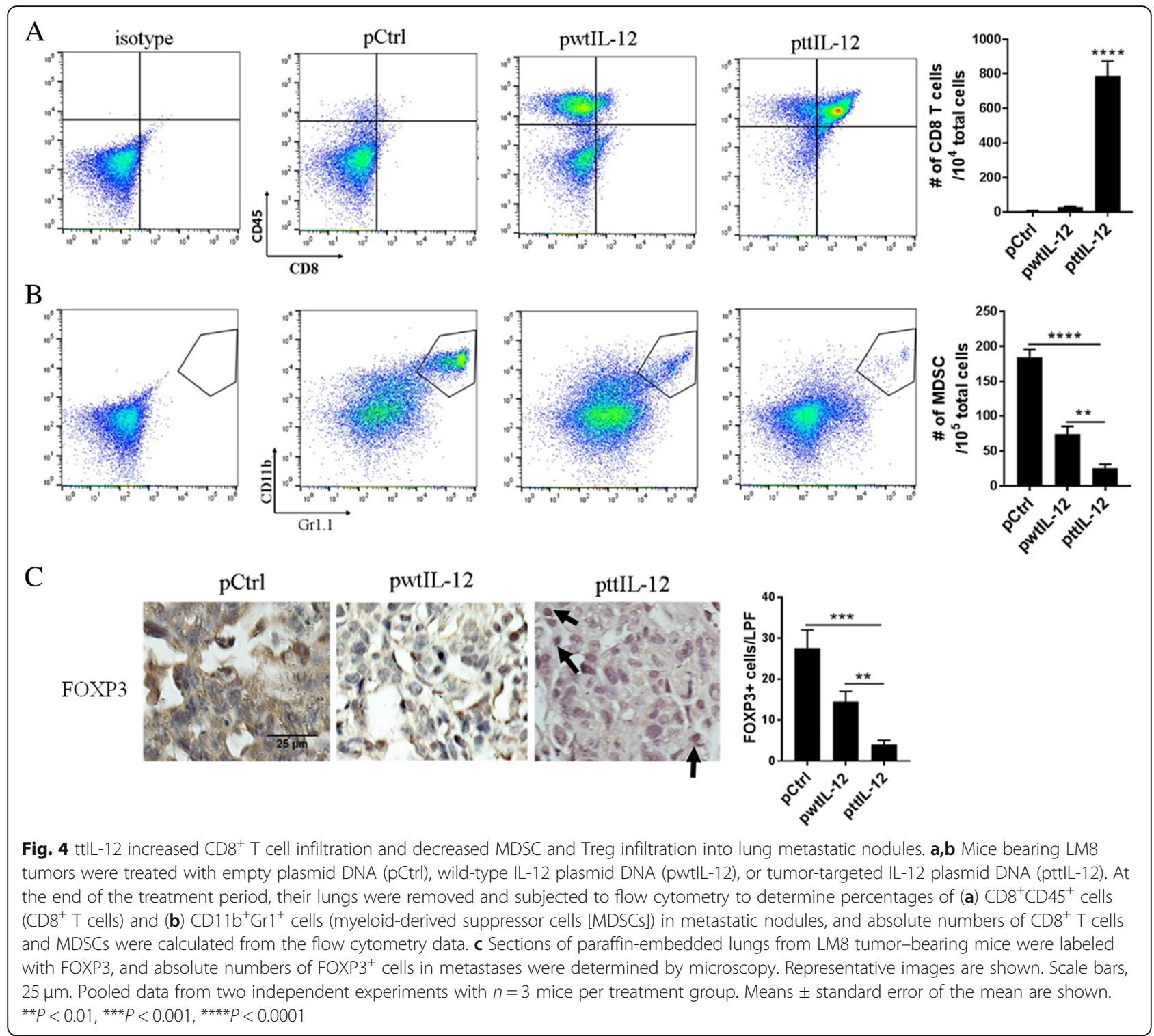

and MDSCs and is associated with reductions in expression of CCL22 and CXCL2 in the tumor microenvironment.

To further verify the impact of these ttIL-12-induced chemokines on recruitment of MDSCs and Tregs into tumors, pCXCL2 and pCCL22 were administered via intramuscular electroporation in the presence of ttIL-12 therapy to $4 \mathrm{~T} 1$ and LM8 tumor-bearing mice. As expected, induced systemic expression of CXCL2 and CCL22 not only decreased frequencies of $\mathrm{CD}^{+} \mathrm{T}$ cells, most of which were $\mathrm{NKG}^{2} \mathrm{D}^{+} \mathrm{CD} 8^{+} \mathrm{T}$ cells, but also increased frequencies of MDSCs and Tregs in tumors, respectively, and partially reversed the impact of ttIL-12 (Fig. 5 and Additional file 1: Figure S7). These results suggest that ttIL-12 converts tumors with a short OS immune profile to the long OS immune profile at least partially through reducing CCL22 and CXCL2 expression.

\section{ttIL-12 treatment coupled with surgery prolongs overall survival}

To verify that inhibition of metastasis and induction of the $\mathrm{CD} 8 \mathrm{a}^{\mathrm{Hi}} \mathrm{IFN} \gamma{ }^{\mathrm{Hi}} \mathrm{CD} 33{ }^{\mathrm{Low}} \mathrm{FOXP} 3{ }^{\mathrm{Low}}$ immune profile by ttIL-12 treatment prolongs OS, we monitored the survival of LM8 and 4 T1 tumor-bearing mice treated with ttIL-12, wtIL-12, or Ctrl in combination with surgery. While both wtIL- $12+\mathrm{S}$ and ttIL- $12+\mathrm{S}$ treatments prolonged survival in the $4 \mathrm{~T} 1$ model compared with $\mathrm{Ctrl}+\mathrm{S}$ treatment $(P<0.0001 ; n=8 \sim 14)$, ttIL-12 $+\mathrm{S}$ treatment led to significantly longer OS than wtIL-12 $+\mathrm{S}$ treatment 


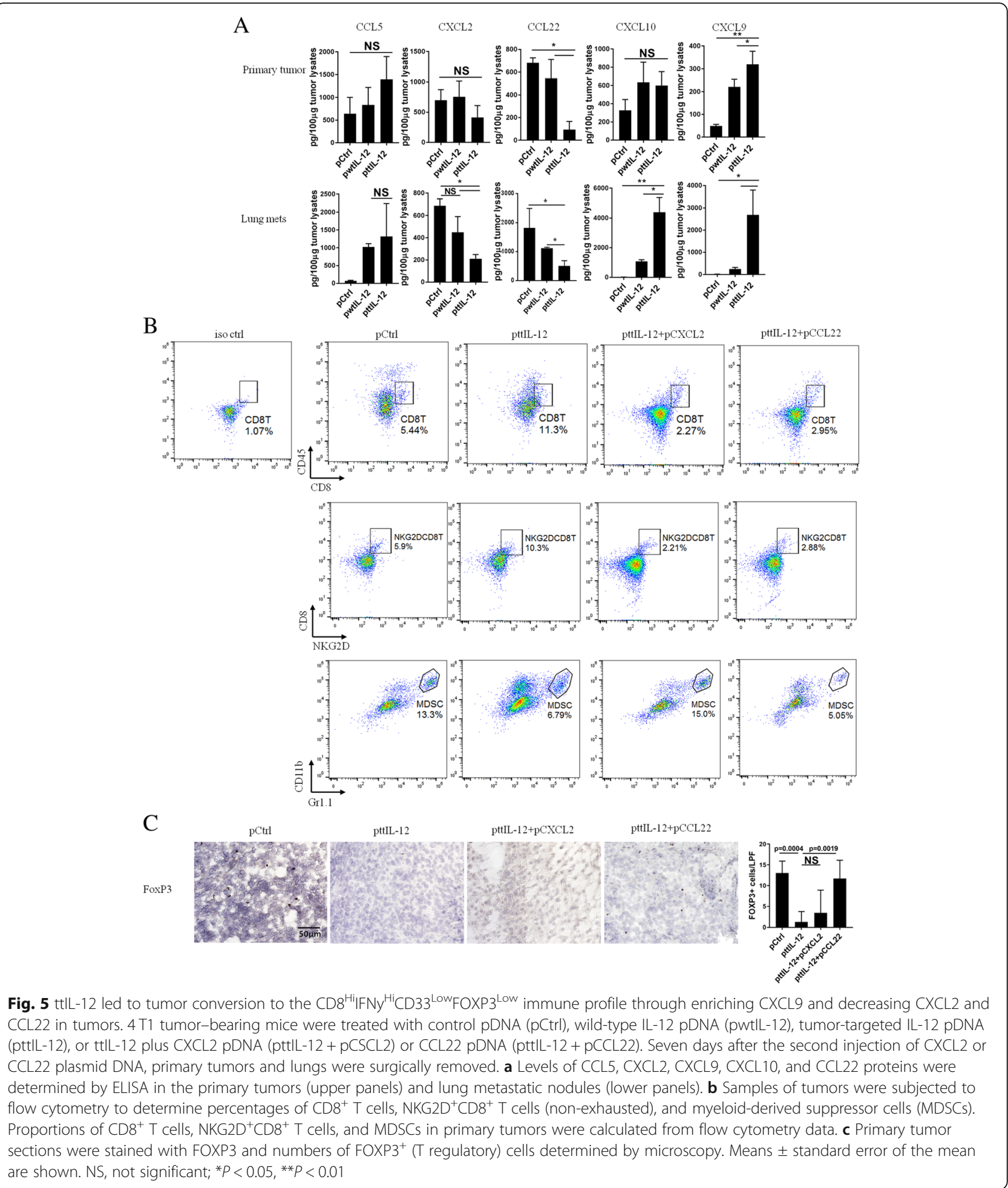

(Fig. 6a; $P=0.0312$ ). In the LM8 model, mice treated with wtIL-12 $+\mathrm{S}$ had curtailed survival compared to those treated with $\mathrm{Ctrl}+\mathrm{S}$; this is attributed at least partly to toxicity, because the host mouse strain $\mathrm{C} 3 \mathrm{H}$ is very sensitive to $\mathrm{IL}-12$ treatment. However, the $\mathrm{C} 3 \mathrm{H}$ mice treated with ttIL-12 $+\mathrm{S}$ showed no evidence of toxicity. The reduced toxicity of ttIL-12 treatment may have been due to lower levels of IL-12 in the serum than in mice treated with wtIL-12 (Additional file 1: Figure S6A). Moreover, $\mathrm{ttIL}-12+\mathrm{S}$ significantly extended the survival 

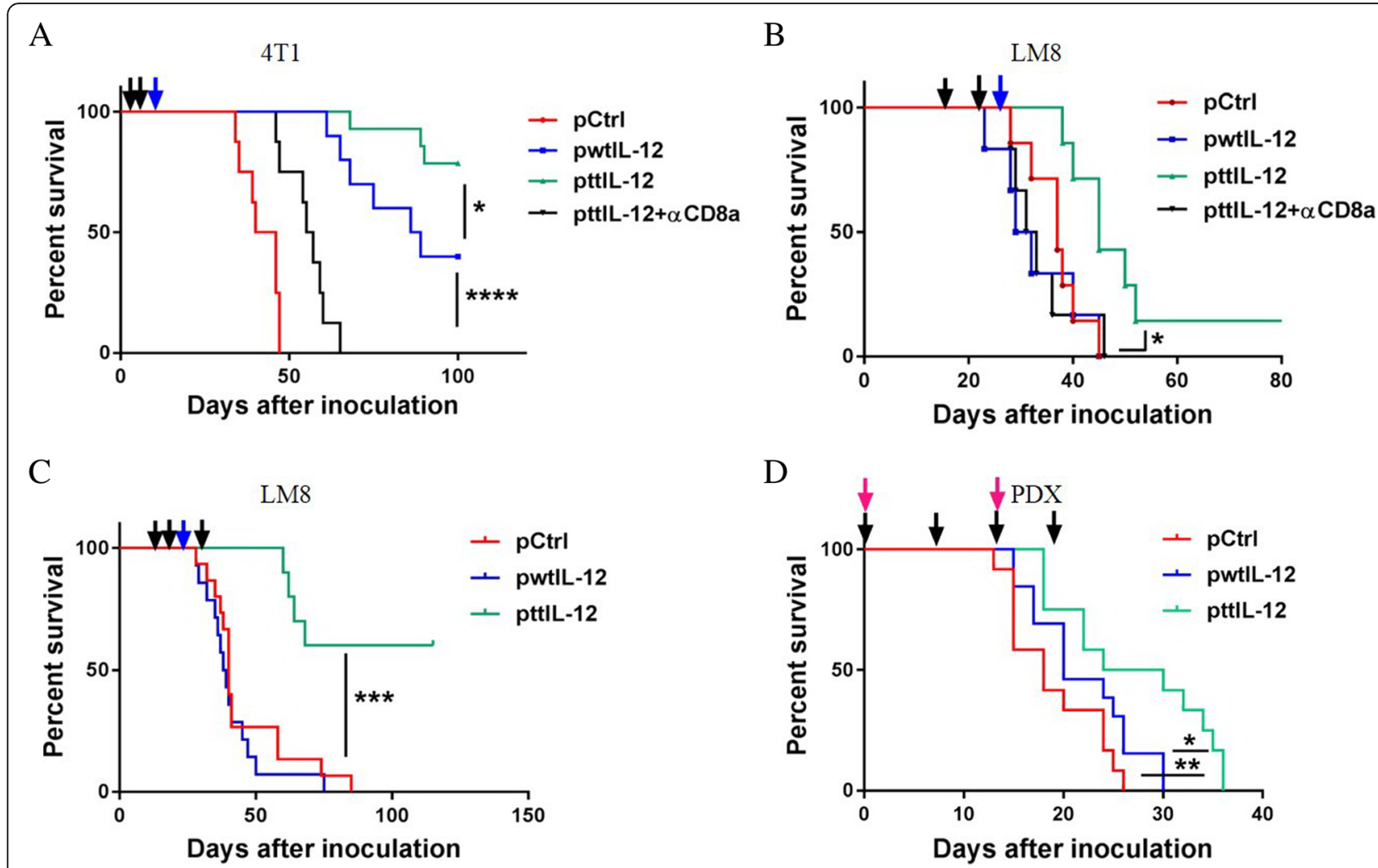

Fig. 6 ttlL-12 prolonged survival compared to wtIL-12 in two independent mouse tumor models and a human tumor model. Overall survival of tumor-bearing mice treated with empty plasmid DNA (pDNA; pCtrl), wild-type IL-12 pDNA (pwtIL-12), tumor-targeted IL-12 pDNA (pttIL-12), or pttlL-12 plus a CD8-depleting antibody (pttIL-12+aCD8a) was determined by using the Kaplan-Meier analysis. Treatment strategy was as described in Fig. 2a. a Overall survival of $4 \mathrm{~T} 1$ tumor-bearing mice by treatment group. b Overall survival of LM8 tumor-bearing mice. c Overall survival of LM8 tumor-bearing mice treated with an extra administration of pDNA 15 days after primary tumor removal. (D) Overall survival of OS60-SJ osteosarcoma patient-derived xenograft (PDX) tumor-bearing mice overall survival. The dark arrows represent pDNA treatment, the blue arrows represent primary tumor removal, and the red arrows represent PBMC injections. Data represent cumulative results from at least two independent experiments. ${ }^{*} P<0.05,{ }^{* *} P<0.01{ }^{* * *} P<0.001,{ }^{* * *} P<0.0001$

of mice compared with both $\mathrm{Ctrl}+\mathrm{S}$ and wtIL- $12+\mathrm{S}$ in these tumor-bearing IL-12-sensitive mice (Fig. 6b) $(P=$ 0.0086 and $P=0.0125$, respectively; $\mathrm{n}=8 \sim 9$ ). To further prolong survival, some LM8 tumor-bearing mice were given ttIL-12 treatment both before and after surgical removal of the primary tumor instead of before surgery only. The extra ttIL-12 treatment after surgery led to a long-term OS rate of $60 \%$ (Fig. $6 \mathrm{c}$ ), showing that ttIL-12 treatment both before and after surgery is more beneficial than ttIL-12 treatment before surgery only.

Furthermore, as shown in Fig. 6d, ttIL-12 significantly prolonged survival of OS60-SJ osteosarcoma tumorbearing mice compared with either Ctrl treatment or wtIL-12 treatment $(P=0.0047$ and $P=0.0295$, respectively; $n=12 \sim 13$ ), which is in line with the results in the other mouse tumor models. Taken together, these results show that ttIL-12 exhibited high potency in transforming the immune profiles in tumors from $\mathrm{IFN}^{\mathrm{Low}}{ }^{\mathrm{C}} \mathrm{C}$ D8 ${ }^{\text {Low }}{ }^{\mathrm{FOXP}} 3{ }^{\mathrm{Hi}} \mathrm{CD} 33^{\mathrm{Hi}}$ to IFN $\gamma{ }^{\mathrm{Hi}} \mathrm{CD} 8{ }^{\mathrm{Hi}} \mathrm{FOXP} 3{ }^{\mathrm{Low}} \mathrm{CD} 33^{\mathrm{Low}}$ and suppressing tumor progress in two mouse tumor models and a human tumor model, indicating that ttIL-12 treatment may have the capacity in prolong the survival of patients with cancer when combined with standard-of-care therapy.

\section{Discussion}

In this study, we discovered that the IFN $\gamma^{\mathrm{Hi}} \mathrm{CD} 8^{\mathrm{Hi}} \mathrm{FOX}$ $\mathrm{P} 3{ }^{\mathrm{Low}} \mathrm{CD} 33^{\mathrm{Low}}$ immune profile in tumors serves as an excellent prognostic marker for OS across human tumor types. In both mouse and human tumor models, ttIL-12 treatment showed higher potency than wtIL-12 in extending survival of tumor-bearing mice and transforming the immune profile from one associated with short OS to the immune profile associated with long OS in these mice. When combined with surgery, ttIL-12 suppressed tumor progression and metastasis in mouse orthotopic tumor models.

Because cancer, particularly solid tumors, is a heterogeneous disease involving disparate aberrant mutations, such as KRAS and BRAF mutations [32], predicting 
clinical outcome from a few mutations is difficult. It is now apodictic that cancer is also diverse by nature of its microenvironmental composition, especially immune cell population and activation status [33]. Most therapeutic strategies against tumors have focused on targeting tumor cells directly [34]; however, immune cells in tumors are genetically stable compared with tumor cells and are probably less susceptible to classic mechanisms of treatment resistance. Given the overwhelming heterogeneity of cancer cells, targeting immunosuppressive markers becomes a compelling therapeutic option.

Immunomodulatory therapy has been shown to be an effective option; antibodies or antagonists that block immune checkpoints, such as the cytotoxic $\mathrm{T}$ lymphocyteassociated antigen 4 (CTLA4) inhibitor ipilimumab [35], programmed death 1 receptor (PD-1) inhibitor nivolumab [36, 37], and programmed death 1 ligand 1 (PD-L1) inhibitor lambrolizumab [38, 39], or chemokine or chemokine receptors inhibitors, such as the CXCchemokine receptor 4 (CXCR4) antagonist LY2510924 [40] and CXCL8 blocker repertaxin [41], have been approved by the U.S. Food and Drug Administration or are being investigated in clinical trials [33, 42]. However, the rate of response to immune checkpoint blockers is low in most tumor types [43]. The mechanism underlying the low response rate is not clear, but it seems that $\mathrm{T}$ cell infiltration into tumors affects the clinical outcome of PD-L1 and PD-1 blockade therapy. The question is how to increase the numbers of $\mathrm{CD} 8^{+} \mathrm{T}$ cells in tumors to overcome this resistance. One of the simplest approaches is to simply administer exogenous $\mathrm{T}$ cells, such as CAR-T cells, but the clinical impact of such treatment against solid tumors is minimal [44]. The poor results may be due to multiple reasons, but one major reason is the failure of the administered $\mathrm{T}$ cells to infiltrate into tumors [45]. Therefore, the therapeutic impact of several chemokines that recruit $\mathrm{CD} 8^{+} \mathrm{T}$ cell into tumors have been explored [46]. As we have found here, CXCL9 and CXCL10 may be important for CD8 ${ }^{+} \mathrm{T}$ cell recruitment (Fig. 5).

High numbers of $\mathrm{CD}^{+}$tumor-infiltrating lymphocytes is often an indicator of good response to various therapies, but not always [47]. Two studies found that a high number of $\mathrm{CD}^{+} \mathrm{T}$ cells was barely associated with clinical outcome [48], which indicates that the presence of $\mathrm{CD}^{+} \mathrm{T}$ cells in tumors will not guarantee tumor eradication and long-term survival. Since poor outcome may be due to $\mathrm{CD}^{+} \mathrm{T}$ cell exhaustion or inactivation, both markers of $\mathrm{CD}^{+} \mathrm{T}$ cell activation/exhaustion and of suppressive immune cells should be included in the optimal prognostic immune profile. Scott et al. found that a high immune gene cluster expression summary score can predict OS [3]. However, second-generation gene sequencing is needed to get the score, which makes it costly and laborious for the prediction of clinical outcome. We found here, through comparing different immune profiles, that the IFN $\gamma{ }^{\mathrm{Hi}} \mathrm{CD} 8^{\mathrm{Hi}} \mathrm{FOXP} 3^{\mathrm{Low}} \mathrm{CD} 33^{\mathrm{Low}}$ immune profile in tumors was a compelling predictor of survival across tumor types. Thus, reprogramming or reeducating tumors to the $\mathrm{IFN} \gamma{ }^{\mathrm{Hi}} \mathrm{CD} 8{ }^{\mathrm{Hi}} \mathrm{FOXP} 3{ }^{\mathrm{Low}} \mathrm{C}$ D33 ${ }^{\text {Low }}$ immune profile may represent an exciting new opportunity in tumor immunotherapy.

Although this study found that treatment with ttIL-12, but not wtIL-12, can effectively convert both primary and metastatic tumors to this long-term survival-associated immune profile (Fig. 6), this treatment alone will not eliminate large primary tumors. Thus, standard-ofcare surgical removal of primary tumors is still needed. We propose that transformation of the immune profile with ttIL-12 may boost the efficacy of other standard-ofcare therapeutic modalities such as chemotherapy, targeted therapy, and radiation; however, this suggestion must be evaluated experimentally. Though a number of IL-12-based therapies, such as IL-12 gene therapy, IL12-transduced autologous fibroblasts, adenovirus encoding IL-12, and a combination of IL-12 and peptide vaccine, are now being evaluated in clinical trials, only a few have shown encouraging results [49]. This may be because the therapeutic dose of IL-12 may induce toxicity due to high IL-12 levels in serum. Thus, reduction of IL-12 levels in serum and induction of IL-12 expression in tumors is a big challenge in overcoming the drawbacks of IL-12 treatment. In our study, ttIL-12 treatment, compared with wtIL-12, induced higher IL-12 levels at the tumor sites and lower IL-12 levels in serum (Fig. 2e, Additional file 1: Figure S6A), which was accomplished by the tumor-anchoring effect of the CSVtargeting carcinoma homing peptide expressed by ttIL12. Offering enhancement of the wtIL-12 antitumor effect and reduction of toxicity, ttIL-12 has promise as a new form of anticancer immunotherapy.

\section{Conclusions}

Tumor CSV-targeted IL-12, when combined with surgery, led to conversion of tumors to the IFN $\gamma^{\mathrm{Hi}} \mathrm{CD} 8^{\mathrm{Hi}-}$ FOXP $3{ }^{\text {Low }} \mathrm{CD} 33^{\mathrm{Low}}$ immune profile, enhancement of the capacity to eliminate relapse/metastasis, and decreased systemic toxicity in both mouse and human tumor models.

\section{Additional file}

Additional file 1: Table S1. Validation of $\mathrm{CD} 8^{\mathrm{Hi}} \mathrm{FNNy}{ }^{\mathrm{Hi}} \mathrm{CD} 33^{\text {Low }}{ }_{\mathrm{FOXP}} 3^{\mathrm{Low}}$ immune profile in TCGA data sets. Figure S1. ttlL-12 enhanced suppression of primary tumor growth. Figure S2. ttlL-12 decreased M2 macrophages in 4 T1 tumors. Figure S3. ttIL-12 enhanced CD8+ T cell infiltration, decreased MDSCs, M2 macrophages infiltration in primary LM8 tumors. Figure S4. ttlL-12 increased activating CD8 T cells and decreased Tregs in lung metastatic nodules. Figure S5. ttIL-12 increased 
NKG2D + CD8+ T cell infiltration and decreased MDSC and Tregs infiltration into liver metastatic nodules. Figure S6. ttIL-12 led enriched CXCL9 and decreased CXCL2 and CCL22 in both primary tumors and metastatic tumors. Figure S7. Overexpression of CXCL2 and CCL22 reversed ttIL-12's efficacy on increasing CD8 T cells and decreasing MDSCs and Tregs in LM8 tumors. Figure S8. ttIL-12 increased IFNy level, enhanced CD8+ T cell infiltration, and decreased MDSCs and Tregs infiltration in osteosarcoma PDX tumors. (DOCX 15277 kb)

\section{Abbreviations}

Arg1: Arginase 1; CCL22: CC-chemokine ligand 22; CCL5: CC-chemokine ligand 5; CSV: Cell-surface vimentin; CTLA4: Cytotoxic T lymphocyteassociated antigen 4; Ctrl: Control pDNA; CXCL10: CXC-chemokine ligand 10; CXCL2: CXC-chemokine ligand 2; CXCL9: CXC-chemokine ligand 9; CXCR4: CXC-chemokine receptor 4; httIL-12: Human ttlL-12; hwtIL-12: Human wtIL-12; IFNY: Interferon-gamma; IL-10: Interleukin-10; IL-12: Interleukin-12; IL35: Interleukin-35; MDSCs: Myeloid-derived suppressor cells; NK: Natural killer; NKG2D: Natural killer group 2D; OS: Overall survival; PBMCs: Peripheral blood mononuclear cells; pCCL22: CCL22 plasmid DNA; PCXCL2: CXCL2 plasmid DNA; PD-1: Programmed death 1 receptor; PD-L1: PD-1 ligand; pDNA: Plasmid DNA; PDX: Patient-derived xenograft; SD: Standard deviation; TCGA: The Cancer Genome Atlas; TGF- $\beta$ : Transforming growth factor beta; Tregs: Regulatory T cells; ttlL-12 + S: ttlL-12 treatment combined with surgery; ttlL-12: Tumor cell surface vimentin-targeted interleukin 12; wtIL-12 + S: wtlL12 treatment combined with surgery; wtlL-12: Wild-type interleukin 12

\section{Publisher's Note}

Springer Nature remains neutral with regard to jurisdictional claims in published maps and institutional affiliations.

\section{Acknowledgments}

We appreciate the Department of Scientific Publications at The University of Texas MD Anderson Cancer Center for helping us edit our manuscript. This research was performed in the Flow Cytometry \& Cellular Imaging Facility, which is supported in part by the National Institutes of Health through MD Anderson's Cancer Center Support Grant CA016672.

\section{Authors' contributions}

$\mathrm{QZ}, \mathrm{JH}$, and SL conceived and designed the experiments. QZ, JH, XX, JC, AM, and $J Y$ conducted the experiments. ZZ, WZ, and RG were responsible for the PDX model. QZ and JH analyzed the data. QZ, SL, KM, JL edited and/or drafted the manuscript. SL supervised the study. All authors have read and approved the final version of the manuscript.

\section{Funding}

This work was supported by the National Institute of Health Grant RO1 CA120895 and RO1 CA200574

\section{Availability of data and materials}

Not applicable.

\section{Ethics approval and consent to participate} Not applicable.

\section{Consent for publication}

Not applicable.

\section{Competing interests}

The authors declare that they have no competing interests.

\section{Author details}

'Department of Pediatrics-Research, The University of Texas MD Anderson Cancer Center, Houston, TX 77030, USA. ${ }^{2}$ Pharmaceutical company of Pfizer in Pearl River, New York, NY 10965, USA. ${ }^{3}$ Department of Gynecologic Oncology and Reproductive Medicine, The University of Texas MD Anderson Cancer Center, Houston, TX 77030, USA. ${ }^{4}$ Department of Pediatric Stem Cell Transplantation and Cellular Therapy, The University of Texas MD Anderson Cancer Center, Houston, TX 77030, USA. ${ }^{5}$ Department of Sarcoma Medical Oncology, The University of Texas MD Anderson Cancer Center, Houston, TX 77030, USA. ${ }^{6}$ Department of Pediatrics-Research, The University of Texas MD
Anderson Cancer Center, 1515 Holcombe Boulevard, Unit 853, Houston, TX 77054, USA.

Received: 28 November 2018 Accepted: 5 June 2019

Published online: 17 June 2019

\section{References}

1. Serrels A, Lund T, Serrels B, Byron A, McPherson RC, von Kriegsheim A, et al. Nuclear FAK controls chemokine transcription, Tregs, and evasion of antitumor immunity. Cell. 2015;163(1):160-73.

2. Grivennikov SI, Greten FR, Karin M. Immunity, inflammation, and cancer. Cell. 2010;140(6):883-99.

3. Scott MC, Temiz NA, Sarver AE, LaRue RS, Rathe SK, Varshney J, et al. Comparative transcriptome analysis quantifies immune cell transcript levels, metastatic progression, and survival in osteosarcoma. Cancer Res. 2018;78(2): 326-37.

4. Ali HR, Chlon L, Pharoah PD, Markowetz F, Caldas C. Patterns of immune infiltration in breast Cancer and their clinical implications: a geneexpression-based retrospective study. PLoS Med. 2016;13(12):e1002194.

5. Mattarollo SR, Loi S, Duret H, Ma Y, Zitvogel L, Smyth MJ. Pivotal role of innate and adaptive immunity in anthracycline chemotherapy of established tumors. Cancer Res. 2011;71(14):4809-20.

6. Oesterreich S, Lucas PC, McAuliffe PF, Bruno TC, Vignali DAA. Opening the door for immune oncology studies in invasive lobular breast Cancer. J Natl Cancer Inst. 2018.

7. Chen DS, Mellman I. Oncology meets immunology: the cancer-immunity cycle. Immunity. 2013;39(1):1-10.

8. Filatenkov A, Baker J, Mueller AM, Kenkel J, Ahn GO, Dutt S, et al. Ablative tumor radiation can change the tumor immune cell microenvironment to induce durable complete remissions. Clin Cancer Res. 2015;21(16):3727-39.

9. Medler TR, Cotechini T, Coussens LM. Immune response to cancer therapy: mounting an effective antitumor response and mechanisms of resistance. Trends Cancer. 2015;1(1):66-75.

10. Ostrand-Rosenberg S, Sinha P, Beury DW, Clements VK, editors. Cross-talk between myeloid-derived suppressor cells (MDSC), macrophages, and dendritic cells enhances tumor-induced immune suppression. Seminars in cancer biology; 2012: Elsevier.

11. Umansky V, Blattner C, Fleming V, Hu X, Gebhardt C, Altevogt P, et al., editors. Myeloid-derived suppressor cells and tumor escape from immune surveillance. Seminars in immunopathology; 2017: Springer.

12. Shatnyeva OM, Hansen HP, Reiners KS, Sauer M, Vyas M, EPv S. DNA damage response and evasion from immunosurveillance in CLL: new options for NK cell-based immunotherapies. Front Genet. 2015;6:11.

13. Sakaguchi $S$, Yamaguchi $T$, Nomura $T$, Ono M. Regulatory $T$ cells and immune tolerance. Cell. 2008;133(5):775-87.

14. Izcue A, Coombes JL, Powrie F. Regulatory T cells suppress systemic and mucosal immune activation to control intestinal inflammation. Immunol Rev. 2006;212(1):256-71.

15. Pretscher D, Distel LV, Grabenbauer GG, Wittlinger M, Buettner M, Niedobitek G. Distribution of immune cells in head and neck cancer: CD8+ T-cells and CD20+ B-cells in metastatic lymph nodes are associated with favourable outcome in patients with oro-and hypopharyngeal carcinoma. BMC Cancer. 2009;9(1):292

16. Meyer C, Cagnon L, Costa-Nunes CM, Baumgaertner P, Montandon N, Leyvraz $\mathrm{L}$, et al. Frequencies of circulating MDSC correlate with clinical outcome of melanoma patients treated with ipilimumab. Cancer Immunol Immunother. 2014;63(3):247-57.

17. Näsman $A$, Romanitan $M$, Nordfors $C$, Grün $N$, Johansson $H$, Hammarstedt L, et al. Tumor infiltrating CD8+ and Foxp3+ lymphocytes correlate to clinical outcome and human papillomavirus (HPV) status in tonsillar cancer. PLoS One. 2012;7(6):e38711.

18. Lasek W, Zagożdżon R, Jakobisiak M. Interleukin 12: still a promising candidate for tumor immunotherapy? Cancer Immunol Immunother. 2014; 63(5):419-35.

19. Cutrera J, Dibra D, Xia X, Hasan A, Reed S, Li S. Discovery of a linear peptide for improving tumor targeting of gene products and treatment of dista tumors by IL-12 gene therapy. Mol Ther. 2011;19(8):1468-77.

20. Satelli A, Mitra A, Brownlee Z, Xia X, Bellister S, Overman MJ, et al. Epithelialmesenchymal transitioned circulating tumor cells capture for detecting tumor progression. Clin Cancer Res. 2015;21(4):899-906. 
21. Hu J, Zhu S, Xia X, Zhang L, Kleinerman ES, Li S. CD8+ T cell-specific induction of NKG2D receptor by doxorubicin plus interleukin-12 and its contribution to CD8+ T cell accumulation in tumors. Mol Cancer. 2014;13(1):34.

22. Hu J, Sun C, Bernatchez C, Xia X, Hwu P, Dotti G, et al. T cell homing therapy for reducing regulatory $T$ cells and preserving effector $T$ cell function in large solid tumors. Clin Cancer Res. 2018; clincanres. 1365.2017.

23. Gabrilovich DI, Ostrand-Rosenberg S, Bronte V. Coordinated regulation of myeloid cells by tumours. Nat Rev Immunol. 2012;12(4):253.

24. Kitamura T, Qian B-Z, Pollard JW. Immune cell promotion of metastasis. Nat Rev Immunol. 2015;15(2):73.

25. Erreni M, Mantovani A, Allavena P. Tumor-associated macrophages (TAM) and inflammation in colorectal cancer. Cancer Microenviron. 2011;4(2):141-54.

26. Serafini P, Mgebroff S, Noonan K, Borrello I. Myeloid-derived suppressor cells promote cross-tolerance in B-cell lymphoma by expanding regulatory $\mathrm{T}$ cells. Cancer Res. 2008;68(13):5439-49.

27. Testi R, D'Ambrosio D, De Maria R, Santoni A. The CD69 receptor: a multipurpose cell-surface trigger for hematopoietic cells. Immunol Today. 1994;15(10):479-83.

28. Mannion BA, Berditchevski F, Kraeft S-K, Chen LB, Hemler ME. Transmembrane-4 superfamily proteins CD81 (TAPA-1), CD82, CD63, and CD53 specifically associated with integrin alpha 4 beta 1 (CD49d/CD29). J Immunol. 1996;157(5):2039-47.

29. Lutz MB, Kukutsch N, Ogilvie AL, Rößner S, Koch F, Romani N, et al. An advanced culture method for generating large quantities of highly pure dendritic cells from mouse bone marrow. J Immunol Methods. 1999;223(1): 77-92.

30. Shalapour S, Karin M. Immunity, inflammation, and cancer: an eternal fight between good and evil. J Clin Invest. 2015;125(9):3347-55.

31. Ma Y, Conforti R, Aymeric L, Locher C, Kepp O, Kroemer G, et al. How to improve the immunogenicity of chemotherapy and radiotherapy. Cancer Metastasis Rev. 2011;30(1):71-82.

32. Richman SD, Seymour MT, Chambers P, Elliott F, Daly CL, Meade AM, et al. KRAS and BRAF mutations in advanced colorectal cancer are associated with poor prognosis but do not preclude benefit from oxaliplatin or irinotecan: results from the MRC FOCUS trial. J Clin Oncol. 2009;27(35):5931-7.

33. Quail DF, Joyce JA. Microenvironmental regulation of tumor progression and metastasis. Nat Med. 2013;19(11):1423.

34. Brannon-Peppas L, Blanchette JO. Nanoparticle and targeted systems for cancer therapy. Adv Drug Deliv Rev. 2012;64:206-12.

35. Hodi FS, O'day SJ, McDermott DF, Weber RW, Sosman JA, Haanen JB, et al. Improved survival with ipilimumab in patients with metastatic melanoma. N Engl J Med. 2010;363(8):711-23.

36. Wolchok JD, Kluger H, Callahan MK, Postow MA, Rizvi NA, Lesokhin AM, et al. Nivolumab plus ipilimumab in advanced melanoma. N Engl J Med. 2013; 369(2):122-33.

37. Johnson DB, Peng C, Sosman JA. Nivolumab in melanoma: latest evidence and clinical potential. Ther Adv Med Oncol. 2015;7(2):97-106

38. Brahmer JR, Tykodi SS, Chow LQ, Hwu W-J, Topalian SL, Hwu P, et al. Safety and activity of anti-PD-L1 antibody in patients with advanced cancer. N Engl J Med. 2012;366(26):2455-65

39. Syn NL, Teng MW, Mok TS, Soo RA. De-novo and acquired resistance to immune checkpoint targeting. Lancet Oncol. 2017;18(12):e731-e41.

40. Galsky MD, Vogelzang NJ, Conkling P, Raddad E, Polzer J, Roberson S, et al. A phase I trial of LY2510924, a CXCR4 peptide antagonist, in patients with advanced cancer. Clin Cancer Res. 2014;20(13):3581-8.

41. Ha H, Debnath B, Neamati N. Role of the CXCL8-CXCR1/2 axis in cancer and inflammatory diseases. Theranostics. 2017;7(6):1543.

42. Prieto J, Melero I, Sangro B. Immunological landscape and immunotherapy of hepatocellular carcinoma. Nat Rev Gastroenterol Hepatol. 2015;12(12):681.

43. Balar AV, Galsky MD, Rosenberg JE, Powles T, Petrylak DP, Bellmunt J, et al. Atezolizumab as first-line treatment in cisplatin-ineligible patients with locally advanced and metastatic urothelial carcinoma: a single-arm, multicentre, phase 2 trial. Lancet. 2017;389(10064):67-76.

44. Newick K, O'Brien S, Moon E, Albelda SM. CAR T cell therapy for solid tumors. Annu Rev Med. 2017;68:139-52

45. Yong CS, Dardalhon V, Devaud C, Taylor N, Darcy PK, Kershaw MH. CAR Tcell therapy of solid tumors. Immunol Cell Biol. 2017;95(4):356-63.

46. Oelkrug C, Ramage J. Enhancement of $T$ cell recruitment and infiltration into tumours. Clin Exp Immunol. 2014;178(1):1-8.

47. Preston CC, Maurer MJ, Oberg AL, Visscher DW, Kalli KR, Hartmann LC, et al. The ratios of CD8+ T cells to CD4+ CD25+ FOXP3+ and FOXP3-T cells correlate with poor clinical outcome in human serous ovarian cancer. PLoS One. 2013;8(11):e80063.

48. Thompson ED, Zahurak M, Murphy A, Cornish T, Cuka N, Abdelfatah E, et al. Patterns of PD-L1 expression and CD8 T cell infiltration in gastric adenocarcinomas and associated immune stroma. Gut. 2016:gutjnl-2015310839.

49. Tugues S, Burkhard SH, Ohs I, Vrohlings M, Nussbaum K, Vom Berg J, et al. New insights into IL-12-mediated tumor suppression. Cell Death Differ. 2015:22(2):237-46

Ready to submit your research? Choose BMC and benefit from:

- fast, convenient online submission

- thorough peer review by experienced researchers in your field

- rapid publication on acceptance

- support for research data, including large and complex data types

- gold Open Access which fosters wider collaboration and increased citations

- maximum visibility for your research: over $100 \mathrm{M}$ website views per year

At $\mathrm{BMC}$, research is always in progress.

Learn more biomedcentral.com/submissions 